\title{
The biomechanical role of periodontal ligament in bonded and replanted vertically fractured teeth under cyclic biting forces
}

\author{
Ya-Nan Zhu ${ }^{1, *}$, Wei-Dong Yang ${ }^{1, *}$, Paul V Abbott ${ }^{2}$, Nicolas Martin ${ }^{3}$, Wen-Jia Wei ${ }^{4}$, Jing-Jing Li ${ }^{5}$, Zhi Chen $^{6}$ \\ and Wen-Mei Wang ${ }^{5}$
}

After teeth are replanted, there are two possible healing responses: periodontal ligament healing or ankylosis with subsequent replacement resorption. The purpose of this study was to compare the fatigue resistance of vertically fractured teeth after bonding the fragments under conditions simulating both healing modes. Thirty-two human premolars were vertically fractured and the fragments were bonded together with Super-Bond C\&B. They were then randomly distributed into four groups (BP, CP, CA, BA). The BP and CP groups were used to investigate the periodontal ligament healing mode whilst the BA and CA groups simulated ankylosis. All teeth had root canal treatment performed. Metal crowns were constructed for the CP and CA groups. The BP and BA groups only had composite resin restorations in the access cavities. All specimens were subjected to a $260 \mathrm{~N}$ load at $4 \mathrm{~Hz}$ until failure of the bond or until $2 \times 10^{6}$ cycles had been reached if no fracture occurred. Cracks were detected by stereomicroscope imaging and also assessed via dye penetration tests. Finally, interfaces of the resin luting agent were examined by scanning electron microscope. The results confirmed that the fatigue resistance was higher in the groups with simulated periodontal ligament healing. Periodontal reattachment showed important biomechanical role in bonded and replanted vertically fractured teeth.

International Journal of Oral Science (2014) 7, 125-130; doi:10.1038/ijos.2014.51; published 12 September 2014

Keywords: ankylosis; fatigue test; periodontal ligament healing; replantation; vertically fractured teeth

\section{INTRODUCTION}

Vertical crown-root fracture of molar and premolar teeth is a common non-caries problem especially following endodontic treatment or when there are cracks in the tooth. ${ }^{1-6}$ Several approaches have been adopted to try and retain vertically fractured posterior teeth, including attempts to splint the fractured segments together using wire. ${ }^{7-8}$ However, this approach has a poor prognosis and no data to support it. No reliable method has been reported for retaining vertically fractured posterior teeth and these teeth are usually extracted.

A multidisciplinary approach combining tooth extraction, bonding of the segments with adhesive material followed by intentional replantation may be an alternative method of managing vertically fractured posterior teeth. Trope \& Rosenberg successfully repaired a vertically fractured upper left second molar using this approach. ${ }^{9}$ After one year, the tooth still functioned normally and had no clinical or radiographic signs of disease.

With the improvement of adhesive dentistry and the availability of materials such as 4-methyl-acryloyl-ethyl-trimellitic anhydride (4-META)/(methyl methacrylate-tributylborane MMA-TBB) resin cement, this treatment approach has been applied to vertically fractured anterior teeth and crown-root fractures in posterior teeth. ${ }^{1-2,10-}$

12 The short-term prognosis following this procedure appears to be reasonable, but it has a poor long-term prognosis. ${ }^{13}$

Replantation is one of the most important steps in this treatment approach. The periodontal ligament (PDL) is injured during extraction of the tooth and, according to Andreasen, ${ }^{14-15}$ this may result in ankylosis and replacement resorption following replantation. There may also be varying reactions of the PDL to the layer of adhesive dental material in the fracture line of the tooth. ${ }^{16}$ The effect of the occlusion is also unknown as there have been no reports in the literature.

The purpose of this study was to explore the biomechanical role of periodontal reattachment in bonded and replanted vertically fractured tooth under cyclic biting force.

\section{MATERIALS AND METHODS}

Fractured teeth specimen preparation

Forty human maxillary upper first premolars with two roots, extracted for orthodontic reasons, without cracks or cavities were used in this

${ }^{1}$ Department of Endodontics, Institute and Hospital of Stomatology, Nanjing University Medical School, Nanjing, China; ${ }^{2}$ Department of Endodontics, School of Dentistry, The

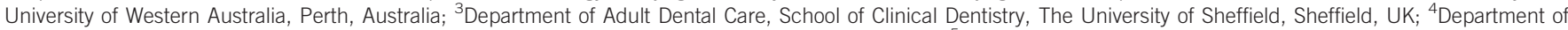

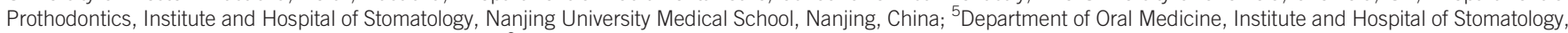
Nanjing University Medical School, Nanjing, China and ${ }^{6}$ Department of Endodontics, The School and Hospital of Stomatology, Wuhan University, Wuhan, China

*These authors contributed equally to this study

Correspondence: Dr WM Wang, Department of Oral Medicine, Institute and Hospital of Stomatology, Nanjing University Medical School, Nanjing 210008, China

E-mail: wenmei-wang@hotmail.com

Accepted 7 July 2014 
study. The teeth were stored in water with $0.5 \%$ chloramine at $4{ }^{\circ} \mathrm{C}$, and used within 1 month following extraction. ${ }^{17}$ The teeth were chosen from a collection of more than 80 premolar teeth so they were all of similar size and dimensions. The length of the teeth, the length from the central fossa to the root furcation, and the angle of the root furcation were measured. Teeth with measurements within $90 \%$ of the medians were chosen. The length of the teeth was $(17.50 \pm 0.70) \mathrm{mm}$. The length from central fossa to root furcation was $(11.00 \pm 0.75) \mathrm{mm}$, and the angle of the root furcation was $16.5^{\circ} \pm 2.5^{\circ}$. The study was independently reviewed and approved by the ethical board of the hospital.

In order to simulate a vertical fracture, the teeth were separated into two halves with a low-speed cutting saw and a blade of $0.2 \mathrm{~mm}$ thickness (Isomet 11-1280-250; Buehler, Lake Bluff, IL, USA) mesiodistally along the vertical axis (Figure 1a). In order to further standardize the specimens, the surface areas of each section were calculated using
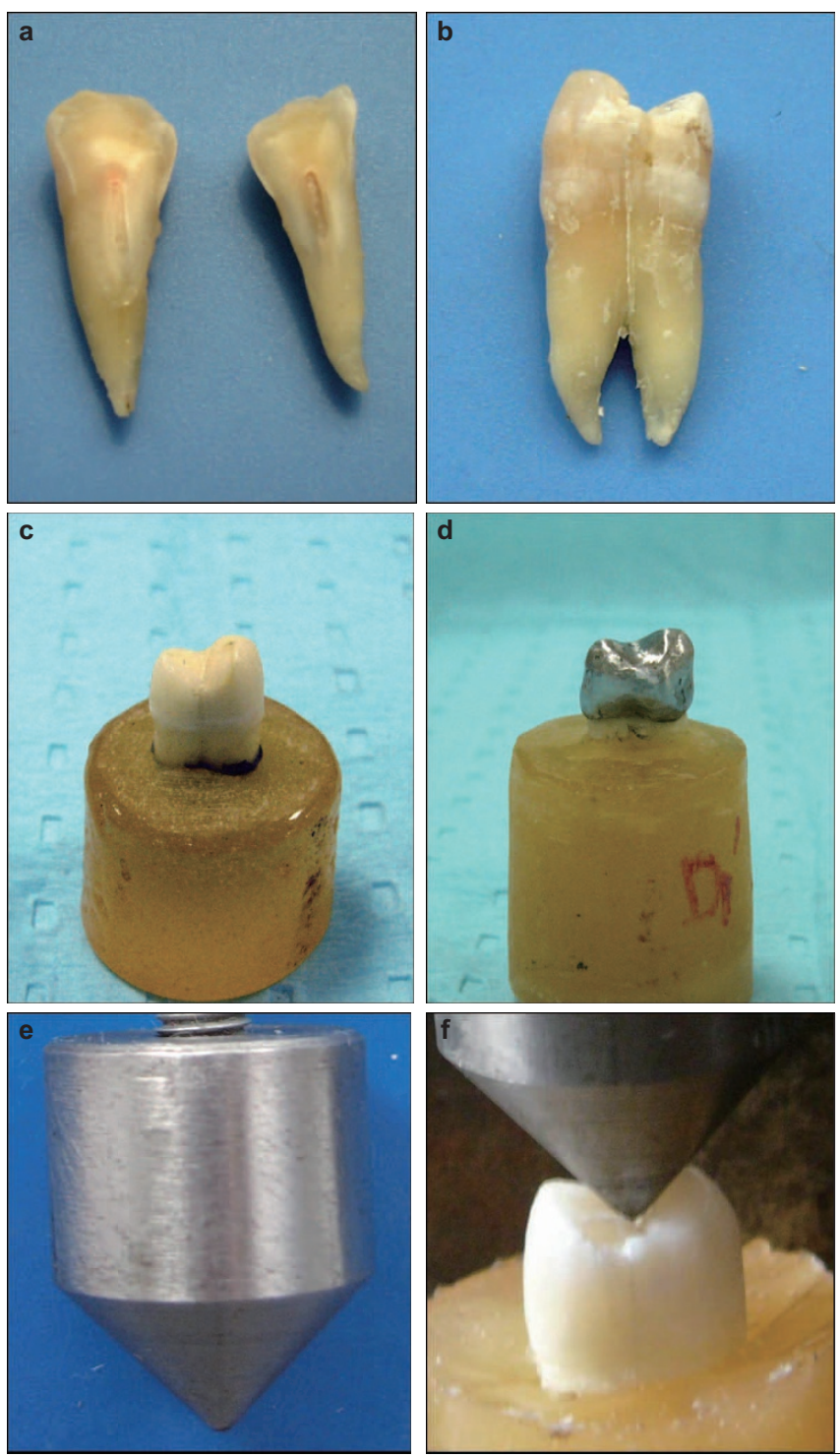

Figure 1 Photos of tooth specimen and cyclic-load device. (a) An example of a tooth showing the direction and location of the vertical cutting. (b) The tooth after bonding the fragments together with Super-Bond C\&B. (c) A tooth specimen without crown restoration. (d) A tooth specimen with the crown restoration. (e) The conical loading instrument with an $80^{\circ}$ angle tip specifically manufactured to imitate the cusp of a premolar. (f) The loading point on the central fossa of the tooth.
Adobe Photoshop CS2. Sections with surface areas within $90 \%$ of the median area were chosen.

The two halves were then bonded together with 4-META/MMATBB resin agent (Super-Bond C\&B; Sun Medical, Tokyo, Japan). Endodontic access cavities were cut and root canal treatment was performed (Figure 1b). The access cavities were then restored with an adhesive bond (Adper Prompt; 3M ESPE, Seefeld, Germany) and composite resin restoration (Filtek Z350; 3M ESPE Dental Products, St. Paul, MN, USA). The teeth were randomly divided into four groups, labelled BP, BA, CP and CA, with each group managed as follows:

- Group BP: bonding, no crown restoration and with periodontal ligament $(n=10)$;

- Group BA: bonding, no crown restoration and ankylosis $(n=10)$;

- Group CP: bonding, Ni-Cr metal full crown restoration and with periodontal ligament $(n=10)$;

- Group CA: bonding, Ni-Cr metal full crown restoration and ankylosis $(n=10)$.

The teeth were embedded in epoxy resin (Phoenix; Blue-star Manufacturing, Wuxi, China) to a level $2 \mathrm{~mm}$ apical to the cementoenamel junction. Two groups (BP and $\mathrm{CP}$ ) had an additional intermediate elastic layer of silicone rubber (Honigum-Mixstar MonoDMG; Dental-Material Gesellschaft, Elbgaustr, Germany) to simulate the periodontal ligament while the groups without this layer (BA and CA) simulated dento-alveolar ankylosis. All specimens formed cylinders $30 \mathrm{~mm}$ high and $20 \mathrm{~mm}$ in diameter (Figure 2). The epoxy resin simulated the alveolar bone. ${ }^{18-19}$

In order to create an even thickness $(0.2-0.3 \mathrm{~mm})$ of silicone rubber simulating the PDL, the roots were immersed in fluid wax and then removed. A layer of $0.2-0.3 \mathrm{~mm}$ wax remained on the root surface. The tooth with the wax was then encased in the epoxy resin block (Figure 1c and 1d). After the resin had cured, the teeth and wax were removed from the block. The wax was removed from the tooth and the tooth was then replaced in the resin block with silicone rubber.

\section{Compression testing}

As part of Standardizations GB/T2569-1995 and GB/T7757-1993, the elastic modulus in compression of rubber and epoxy resin were measured with a Universal Testing Instrument (Instron 4466; Instron, Hensgrand, MA, USA). Rectangular parallel specimens $10 \mathrm{~mm} \times 10 \mathrm{~mm} \times 20 \mathrm{~mm}$ were prepared. Those specimens with smooth surface, no cracks, no obvious defects such as impurities and processing damage were considered

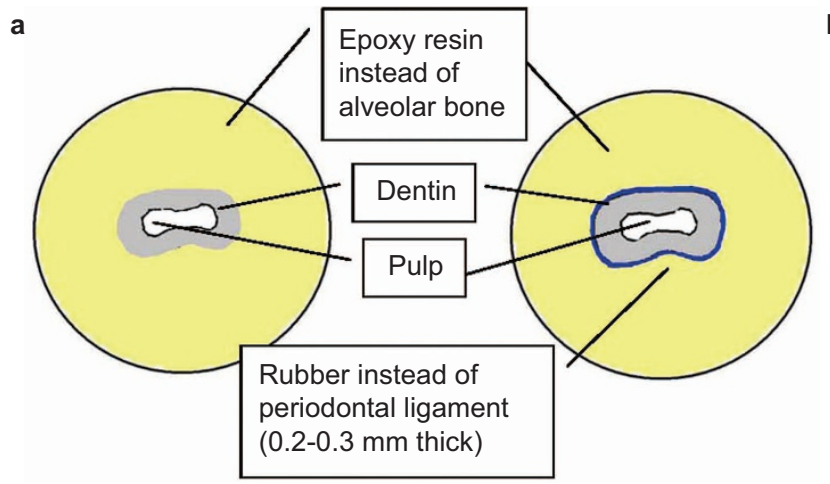

Figure 2 Conceptual diagram of the model used. (a) The model used for the ankylosis healing group; (b) the model used for the periodontal ligament healing group. 

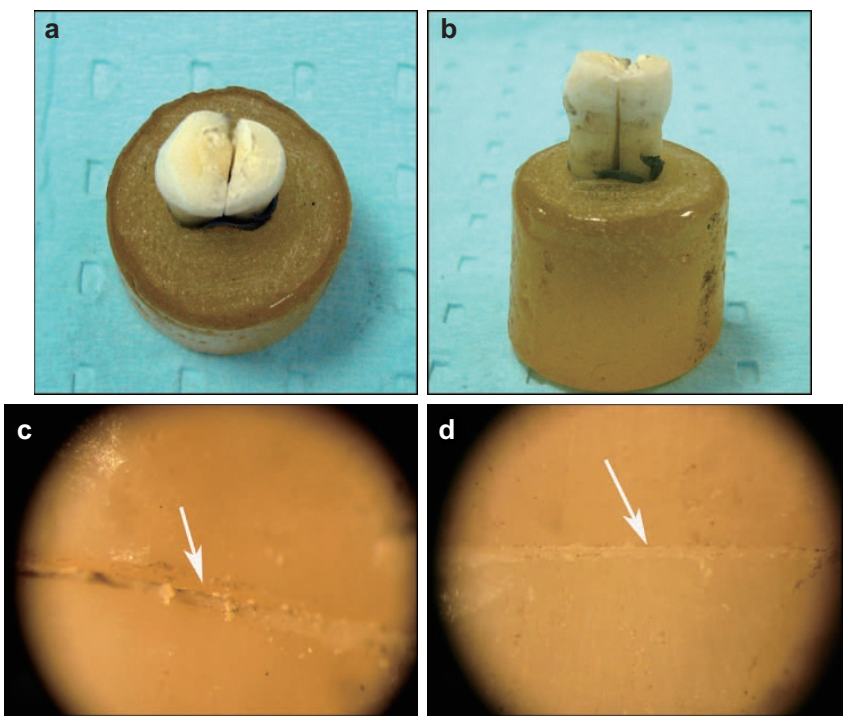

Figure 3 Three results after cyclic loading. (a and $\mathbf{b}$ ) 'Broke': an example of a specimen without a metal crown that broke completely after fatigue loading. (c) 'Crack': typical appearances of the bonding layer crack under stereomicroscope $(\times 50)$. (d) 'No failure': the image of the bonding layer without cracks under stereomicroscope $(\times 50)$.

suitable for testing. The specimens were stored for $24 \mathrm{~h}$ under standard ambient conditions at $(23 \pm 2){ }^{\circ} \mathrm{C}$ and $50 \% \pm 5 \%$ humidity. The elastic modulus of the rubber and epoxy resin were based on this compression test. The load, displacement, stress, strain rate and the modulus were recorded.

\section{Cyclic-load testing}

Cyclic-load testing was performed with a cyclic-loading device (K655; Tokyo Giken, Tokyo, Japan) simulating clinical biting conditions. The conical loading instrument, as shown in Figure 1e, was manufactured specifically for this experiment. The angle of the apex is $80^{\circ}$ to imitate the typical cusp of premolar teeth. An instant force of $260 \mathrm{~N}$ was applied to each specimen at $4 \mathrm{~Hz} .{ }^{17}$ Figure $1 \mathrm{f}$ shows the loading point that was situated in the central fossa of the teeth. There is a viewing computer screen attached to the testing machine and the values of load, frequency, amplitude and rate were displayed on the screen in real time. At the end of loading, three results were possible and were recorded as 'broken', 'cracked' and 'no failure'. In Groups BP and BA, a clearly 'broken' specimen that was visible to the naked eye is shown in Figure $3 \mathrm{a}$ and $3 \mathrm{~b}$. The number of load cycles was recorded when the bonding layer broke completely. Data were presented as means \pm standard deviation and were compared using Mann-Whitney $U$ test at a 95\% level of confidence.

No complete breakages occurred in Groups CP and CA after $2 \times 10^{6}$ repetitions. ${ }^{20}$ The loading test was stopped and the teeth were examined under a stereomicroscope $(\times 50$; Wild Heerbrugg Type 308700; Euromex, Heerbrugg, Switzerland) in order to assess them for a 'crack' (Figure 3c) or 'no failure' (Figure 3d).

All statistical analyses were carried out using the statistical software (SPSS, Chicago, IL, USA). Comparisons between Groups CP and CA were performed using Fisher exact probabilities in $2 \times 2$ table. $P<0.05$ was considered to be statistically significant.

\section{Fluid penetration test}

Specimens recorded as 'no failure' after cyclic-loading testing were subsequently tested for fluid penetration. There were 13 samples tested in this manner-nine from Group BP and four from Group BA. Another set of 13 specimens, prepared in the same manner but not subjected to fatigue loading were used as a control group for this test. The apical foramen of each sample was sealed with wax and the root surface, except the bonded layer, was coated with nail polish to seal the cementum, dentine tubules and any lateral canals. The specimens were stored in artificial saliva (Bioxtra Healthcare, Weesp, Belgium) at $37{ }^{\circ} \mathrm{C}$ for 1 week. They were then immersed in a $1 \%$ solution of methylene blue dye at $37{ }^{\circ} \mathrm{C}$ for $48 \mathrm{~h}^{21}$ After being rinsed in tap water, each tooth was separated into two parts transversally $3 \mathrm{~mm}$ above the root furcation (Figure $4 \mathrm{~b}$ and $4 \mathrm{c}$ ). The crown was also sectioned, again transversally (Figure 4d). The root was sectioned vertically through its long axis in the buccolingual plane using a diamond blade (Isomet 111280-250; Buehler, Lake Bluff, IL, USA) (Figure 4d). The depth of dye penetration beneath the enamel or dentine margins in the two locations was measured under a stereomicroscope at $\times 50$ magnification. Two independent-samples test was used to determine the variance of the depths of two groups and two locations.

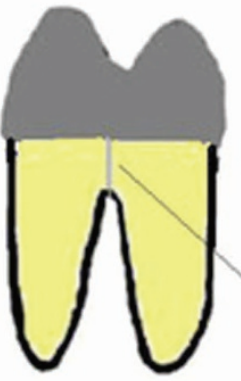

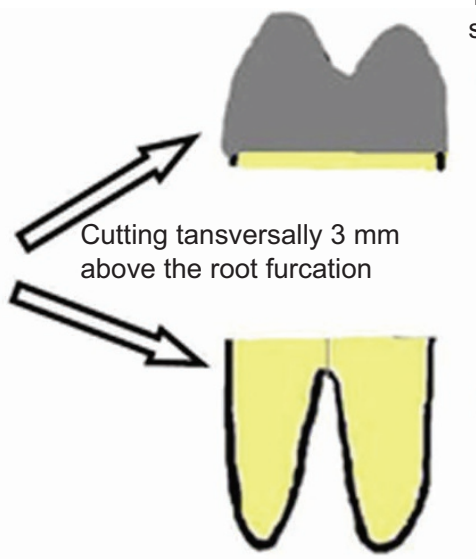

Cutting tansversally $3 \mathrm{~mm}$
Transversal d section

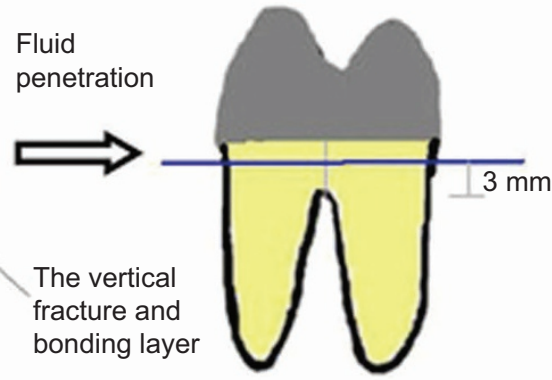

Fluid

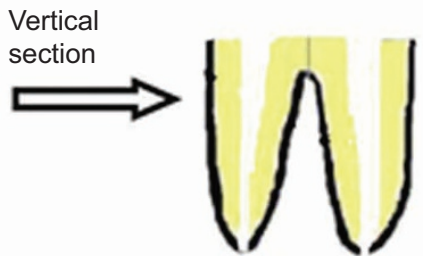

Figure 4 Conceptual diagram of the section direction in the fluid penetrating testing. (a) The specimens were stored in artificial saliva at $37{ }^{\circ} \mathrm{C}$ for a period of 1 week and were then immersed in a $1 \%$ solution of methylene blue dye at $37{ }^{\circ} \mathrm{C}$ for $48 \mathrm{~h}$. (b and $\mathbf{c}$ ) The teeth were separated into two parts transversally $3 \mathrm{~mm}$ above the root furcation. (d) The crown was also sectioned, again transversally and the root was sectioned through its long axis in the buccolingual plane using a diamond blade. 


\section{Scanning electron microscopy}

Those specimens with or without cracks in Group CP and CA were also examined under scanning electron microscopy (SEM) (JSM 6300; Zeisse, Oberkocher, Germany). First the teeth were transected, and then all specimens were mounted on aluminum stubs and sputtercoated with gold. The bonding layers and the dentin/resin interfaces were observed under SEM.

\section{RESULTS}

\section{Compression testing}

The values of the compression test including the load, displacement, stress, strain rate and the elastic modulus are shown in Table 1. The elastic modulus of the rubber was $(13.9 \pm 0.7) \mathrm{MPa}$, and the epoxy resin was $(1.43 \pm 0.17) \mathrm{GPa}$. The values were similar to those of periodontal ligament $(10 \mathrm{MPa})$ and alveolar bone $(1.370 \mathrm{GPa})$, respectively. ${ }^{22}$

\section{Cyclic-load testing}

Completely different results were evident in the specimens with or without metal crown restorations. In the BP and BA groups without crowns, all fractures occurred in the bonding layer (Figure 5). The load cycles of the BP group (150 580 21570 ) were significantly larger than the BA group $(29268 \pm 9473)(P<0.001)$. However, in the other two groups with crown restoration, no fractures were observed in the bonding layer (Table 2). One specimen in the CP group and six in the CA group had cracks when examined under stereomicroscope. The others remained intact for the $2 \times 10^{6}$ repetitions. Fisher exact probabilities in $2 \times 2$ table revealed a significant difference between Groups CP and CA $(P<0.05)$.

Table 1 Results of the compression testing

\begin{tabular}{lcc}
\hline Materials physical quantities & Rubber & Epoxy resin \\
\hline Load at maximum/kN & $0.501 \pm 0.001$ & $6.999 \pm 0.294$ \\
Displacement at maximum/mm & $2.568 \pm 0.306$ & $1.414 \pm 0.132$ \\
Stress at maximum/MPa & $4.838 \pm 0.430$ & $66.620 \pm 4.488$ \\
Strain at maximum/\% & $34.535 \pm 2.750$ & $5.713 \pm 0.303$ \\
Modulus/MPa & $13.944 \pm 0.699$ & $1428.668 \pm 170.090$ \\
\hline
\end{tabular}

Result showed as mean \pm standard devision.

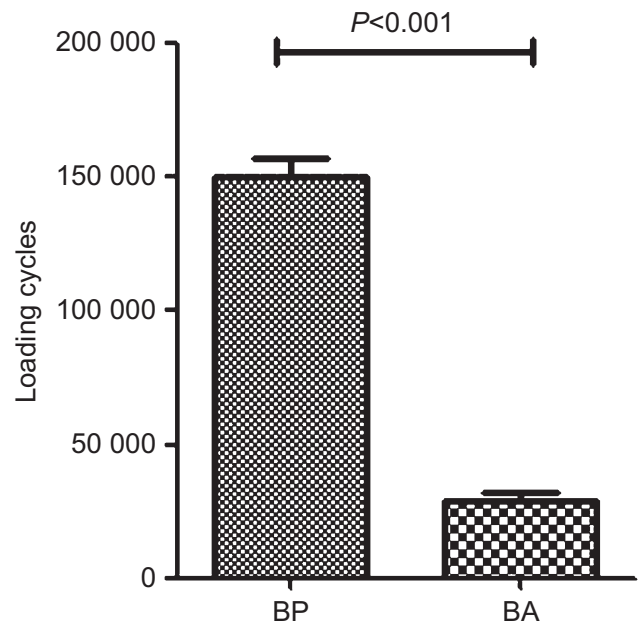

Figure 5 Results of load cycles of Groups BP and BA. There is significant difference in fatigue cycles between Groups BP and BA $(P<0.05)$. Group BP experienced significantly more fatigue cycles than group $B A$.
Table 2 Results of cyclic-load testing in Groups CP and CA

\begin{tabular}{lccc}
\hline & \multicolumn{2}{c}{ Number (percentage/\%) } & \\
\cline { 2 - 3 } Group & No failure & Crack & Total \\
\hline CP & $9(90 \%)$ & $1(10 \%)$ & 10 \\
CA & $4(40 \%)$ & $6(60 \%)$ & 10 \\
Total & 13 & 7 & 20 \\
$* P=0.029$ & & & \\
\hline
\end{tabular}

* $P$ value was calculated using Fisher's exact probabilities in $2 \times 2$ table.

\section{Fluid penetration}

Dye penetration depths observed in the loaded and control groups are presented in Figure 6. Statistical analysis showed no significant difference in depth of dye penetration at the transverse section of the crown between the loaded and the control group $(P>0.05)$. However, for the root furcation vertical sections, the loaded group experienced significantly more dye penetration than the control group $(P<0.001)$. On the other hand, there was no significant difference in depth of dye penetration between the transverse section and the vertical section in the control group $(P>0.05)$. In the loaded group the depth of dye penetration at the vertical section was significantly deeper than the transverse section of the crown $(P=0.001)$.

\section{SEM observation}

SEM indicated that the dentin/resin interfaces broke between the smear layer and the bonding agent. Microscopic cracks were found inside the bonding agent even in those specimens that looked intact under a stereomicroscope. Figure 7 presents scanning electron microscope images of cross-sections of the dentin/bonding agent interface. Images a $(\times 300), b(\times 800)$ and $c(\times 2000)$ zoom in on an apparently undamaged specimen after submitting it to the cyclic-loading test. The fracture is between the smear layer and the bonding agent. Image $\mathrm{d}$ shows the bonding layer without cracks $(\times 1500)$. Image e shows a smear layer without cracks $(\times 2000)$. Image $f$ shows a series of microscopic cracks found inside the bonding agent of another specimen $(\times 2000)$.

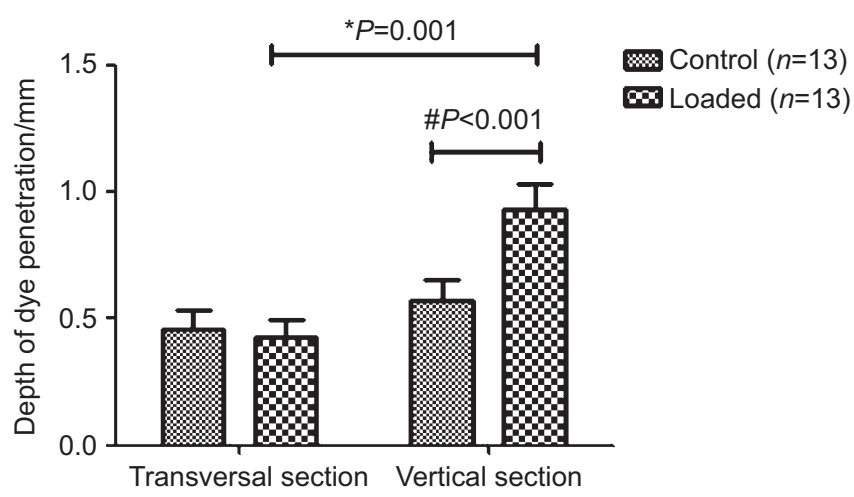

Figure 6 The result of fluid penetration. At the vertical section of root furcation, the loaded group experienced significantly more dye penetration than the control group ( ${ }^{P} P<0.001$ ). In the loaded group, the depth of dye penetration at the vertical section experienced significantly deeper than the transversal section of crown $(* P=0.001)$. 

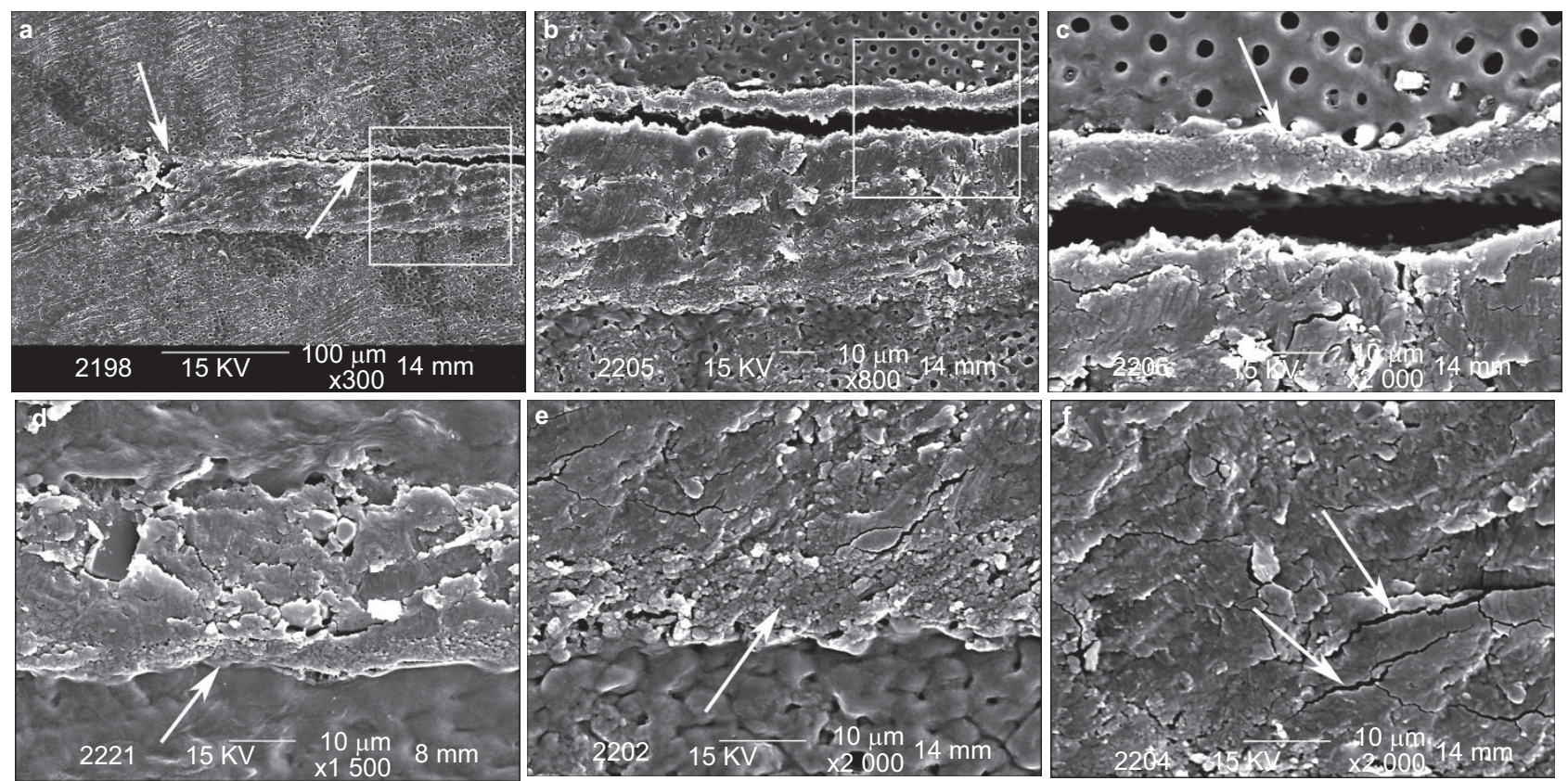

Figure 7 Scanning electron microscope images of cross-sections of the dentin/bonding agent interface. (a, b, c) Zoom in on an apparently undamaged specimen after submitting it to the fatigue test $(\times 300, \times 800, \times 2000)$. The fracture is between the smear layer and the luting agent. (d) Shows the bonding layer without cracks ( $\times 1500$ ). (e) Shows a smear layer without cracks ( $\times 2000)$. (f) Shows a series of microscopic cracks found inside the luting agent of another specimen ( $\times 2000)$.

\section{DISCUSSION}

The multidisciplinary treatment of vertically fractured teeth requires several procedures including extraction, bonding and replantation. Predictably, success involves disinfection of the fractured segments, bonding them to an acceptable clinical strength with a biocompatible material, and maintaining the health of the tooth with periodontal reattachment at the bonded fracture site. Two kinds of PDL response can occur-either normal PDL or ankylosis state-after replantation according Andreasen et al. ${ }^{14,23-24}$ This may be one of the most important factors for cyclic-loading resistance of the bonding layer and the long-term prognosis of vertically fractured teeth.

This in vitro study examined the cyclic-loading resistance of bonded, vertically fractured premolars with and without crown restoration, in a setting simulating two different PDL states.

The oral cavity is a complicated biomechanical environment and tooth fracture is caused by an equally complicated mechanical process. Complete vertical fractures occur most frequently in molars, followed by premolars. The position, direction and depth of the fracture may vary considerably. In order to make the tests reproducible, this study focused on a very similar set of upper first premolars of adolescent humans aged 14-20 years old with two roots. These teeth were chosen because of their ready availability. According to the literature, vertical fractures occur frequently in the middle-aged population but intact premolars are not easy to obtain from middle-aged people. Although different ages may mean differences in organic matter and different reactions to bonding agents, the standardisation of teeth from one age group implies that they are likely to they perform consistently. No effect was shown in the relationship of the cyclic-loading resistance and the PDL state. The 4META/MMA-TBB resin is not affected by blood contamination, has a high tensile strength and is biocompatibile ${ }^{25-27}$-hence, it was selected to bond the vertical fractures in this study. Its high bonding strength is due to the active component, 4-META. This compound has both hydrophilic and hydrophobic properties. Acid anhydride groups are strongly polarized by these molecules, which increases the wettability of the resin.

This research aimed to simulate the clinical station, so the methodology, especially the model was critical. Firstly, in order to simulate the vertical fracture as seen clinically, several approaches were tested in preliminary experiments. Although it is impossible to exactly reproduce clinical fractures, the method outlined was chosen because it was repeatable, and convenient. It also ensured that there was no difference between the samples regarding the direction of fracture and the areas available for bonding.

The two types of PDL conditions were difficult to mimic. A layer of silicone rubber surrounding the tooth was used to simulate a fully healed periodontal ligament. The surrounding epoxy resin played the role of alveolar bone. Since their elastic modulus are similar, the artificial materials and the natural tissues function similarly in transmitting stress. ${ }^{22}$ The epoxy resin used in this experiment was very closely adapted to the teeth and no mobility was detected-hence, the model was used to mimic ankylosis.

The results of cyclic-loading testing showed that crown restoration and functional healing of the periodontal tissues are both of critical importance for long-term retention of vertically fractured teeth. The health of the periodontal tissues decreases the effect of repeated stresses on the bonding agent, in addition to being desirable for its own sake. Threedimensional finite element analysis of premolars in normal occlusion has shown that vertical stress on the tooth always occurs around the root apex and in the wall of the root furcation. ${ }^{28}$ The repaired periodontal ligament acts as a buffer between the hard dental tissues and the alveolar bone. It absorbs shocks, dispersing the stress on the dentin. This is of great significance to the cyclic-loading resistance of the bonding layer.

Cyclic-loading testing changed the microscopic structure of the bond to some extent in most specimens and the SEM evaluation supported this finding. If the resin broke, the fracture always occurred 
between the hybrid layer and the luting agent. This region is thought to be the main weakness of the bonding layer. ${ }^{29-30}$ Under SEM examination, microscopic cracks were found inside the bonding resin, but these defects did not appear to greatly influence the cyclic-loading resistance and stability of the bonding agent. Thus, the prognosis for vertically fractured teeth with crowns and functional healing of the periodontal tissues may be favourable.

As previously mentioned, taking into account the limitations of this in vitro model and the cyclic-loading test procedure, a better model duplicating the true clinical situation should be explored and future research should be carried out to support these findings. However, the results of this study support the conclusion that periodontal reattachment can benefit the prognosis of bonded fractured teeth from the point of view of biomechanics.

With advances in dental science, such as better storage media for maintaining the periodontal health of avulsed teeth, high-strength and relatively biocompatible bonding agents, and barrier techniques aiding the establishment of reattachment on denuded root surfaces, the long term restoration and retention of vertically fractured posterior teeth may be as possible.

\section{ACKNOWLEDGEMENTS}

This work was supported by the Jiangsu Province's Outstanding Medical Academic Leader Program (No. LJ201110), the National Natural Scientific Foundation of China (81070839) and Key Project supported by Medical Science and Technology Development Foundation, Nanjing Department of Health (ZKX10030).

1 Hayashi M, Kinomoto $\mathrm{Y}$, Takeshige $\mathrm{F}$ et al. Prognosis of intentional replantation of vertically fractured roots reconstructed with dentin-bonded resin. J Endod 2004; 30(3): 145-148.

2 Hayashi M, Kinomoto $\mathrm{Y}$, Miura $\mathrm{M}$ et al. Short-term evaluation of intentional replantation of vertically fractured roots reconstructed with dentin-bonded resin. J Endod 2002; 28(2): 120-124.

3 Eichelsbacher F, Denner W, Klaiber B et al. Periodontal status of teeth with crown-root fractures: results two years after adhesive fragment reattachment. J Clin Periodontol 2009; 36(10): 905-911.

4 Lynch CD, Burke FM. Incomplete tooth fracture following root-canal treatment: a case report. Int Endod J 2002; 35(7): 642-646.

5 Vinckier F, Peumans M, Declerck D et al. [Definitive injuries to the teeth. Lesions of hard tissue and pulp.] Rev Belge Med Dent (1984) 1998; 53(2): 29-91. French.

6 Majid ZA, Zain RB. The cracked tooth syndrome-crown root vertical fracture. Singapore Dent J 1988; 13(1): 44-46.

7 Yokoyama K, Matsumoto K, Kinoshita J et al. Treatment of maxillary molars with vertical fractures. Endod Dent Traumatol 1998; 14(6): 287-289.

8 Takatsu T, Sano H, Burrow MF. Treatment and prognosis of a vertically fractured maxillary molar with widely separated segments: a case report. Quintessence Int 1995; 26(7): 479-484.
9 Trope M, Rosenberg ES. Multidisciplinary approach to the repair of vertically fractured teeth. J Endod 1992; 18(9): 460-463.

10 Kawai K, Masaka N. Vertical root fracture treated by bonding fragments and rotational replantation. Dent Traumatol 2002; 18(1): 42-45.

11 Kudou Y, Kubota M. Replantation with intentional rotation of a complete vertically fractured root using adhesive resin cement. Dent Traumatol 2003; 19(2): 115-117.

12 Fariniuk LF, Ferreira EL, Soresini GC et al. Intentional replantation with 180 degrees rotation of a crown-root fracture: a case report. Dent Traumatol 2003; 19(6): 321-325.

13 Masaka N. Long-term observation of fractured tooth roots preserved by adhesion. Adhesion Dent 1995; 13: 156-170.

14 Andreasen JO, Hjorting-Hansen E. Replantation of teeth. II. Histological study of 22 replanted anterior teeth in humans. Acta Odontol Scand 1966; 24(3): 287-306.

15 Andreasen JO, Borum MK, Jacobsen HL et al. Replantation of 400 avulsed permanent incisors. 4. Factors related to periodontal ligament healing. Endod Dent Traumatol 1995; 11(2): 76-89.

16 Sugaya $\mathrm{T}$, Kawanami M, Noguchi $\mathrm{H}$ et al. Periodontal healing after bonding treatment of vertical root fracture. Dent Traumatol 2001; 17(4): 174-179.

17 de Munck J, van Landuyt KL, Coutinho E et al. Fatigue resistance of dentin/composite interfaces with an additional intermediate elastic layer. Eur J Oral Sci 2005; 113(1): 77-82.

18 Kishen A. Periapical biomechanics and the role of cyclic biting force in apical retrograde fluid movement. Int Endod J 2005; 38(9): 597-603.

19 Kishen A, Ramamurty U, Asundi A. Experimental studies on the nature of property gradients in the human dentine. J Biomed Mater Res 2000; 51(4): 650-659.

20 Cohen BI, Deutsch AS, Musikant BL. Cyclic fatigue testing of six endodontic post systems. J Prosthodont 1993; 2(1): 28-32.

21 Gerdolle DA, Mortier E, Loos-Ayav C et al. In vitro evaluation of microleakage of indirect composite inlays cemented with four luting agents. J Prosthet Dent 2005; 93(6): 563-570.

22 Yu WJ, Kwon TY, Kyung HM et al. An evaluation of localized debonding between fibre post and root canal wall by finite element simulation. Int Endod J 2006; 39(12): 959967.

23 Andreasen JO, Paulsen HU, Yu Z et al. A long-term study of 370 autotransplanted premolars. Part III. Periodontal healing subsequent to transplantation. Eur J Orthod 1990; 12(1): 25-37.

24 Pohl Y, Filippi A, Kirschner H. Results after replantation of avulsed permanent teeth. II. Periodontal healing and the role of physiologic storage and antiresorptiveregenerative therapy. Dent Traumatol 2005; 21(2): 93-101.

25 Dean JA, Bullard G, Long RW et al. Dental fracture fragment attachment: fracture model and luting agent comparisons. J Indiana Dent Assoc 2004; 83(1): 7-12.

26 Yang B, Ludwig K, Adelung R et al. Micro-tensile bond strength of three luting resins to human regional dentin. Dent Mater 2006; 22(1): 45-56.

27 Tanaka S, Sugaya T, Kawanami M et al. Hybrid layer seals the cementum/4-META/ MMA-TBB resin interface. J Biomed Mater Res Part B App/ Biomater 2007; 80(1): $140-145$.

28 Borcic J, Anic I, Smojver I et al. 3D finite element model and cervical lesion formation in normal occlusion and in malocclusion. J Oral Rehabil 2005; 32(7): 504-510.

29 Sano H, Takatsu T, Ciucchi B et al. Nanoleakage: leakage within the hybrid layer. Oper Dent 1995; 20(1): 18-25.

30 Sano $\mathrm{H}$, Yoshiyama M, Ebisu S et al. Comparative SEM and TEM observations of nanoleakage within the hybrid layer. Oper Dent 1995; 20(4): 160-167.

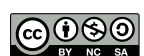

This work is licensed under a Creative Commons AttributionNonCommercial-ShareAlike 3.0 Unported License. The images or other third party material in this article are included in the article's Creative Commons license, unless indicated otherwise in the credit line; if the material is not included under the Creative Commons license, users will need to obtain permission from the license holder to reproduce the material. To view a copy of this license, visit http://creativecommons.org/licenses/by-nc-sa/3.0/ 